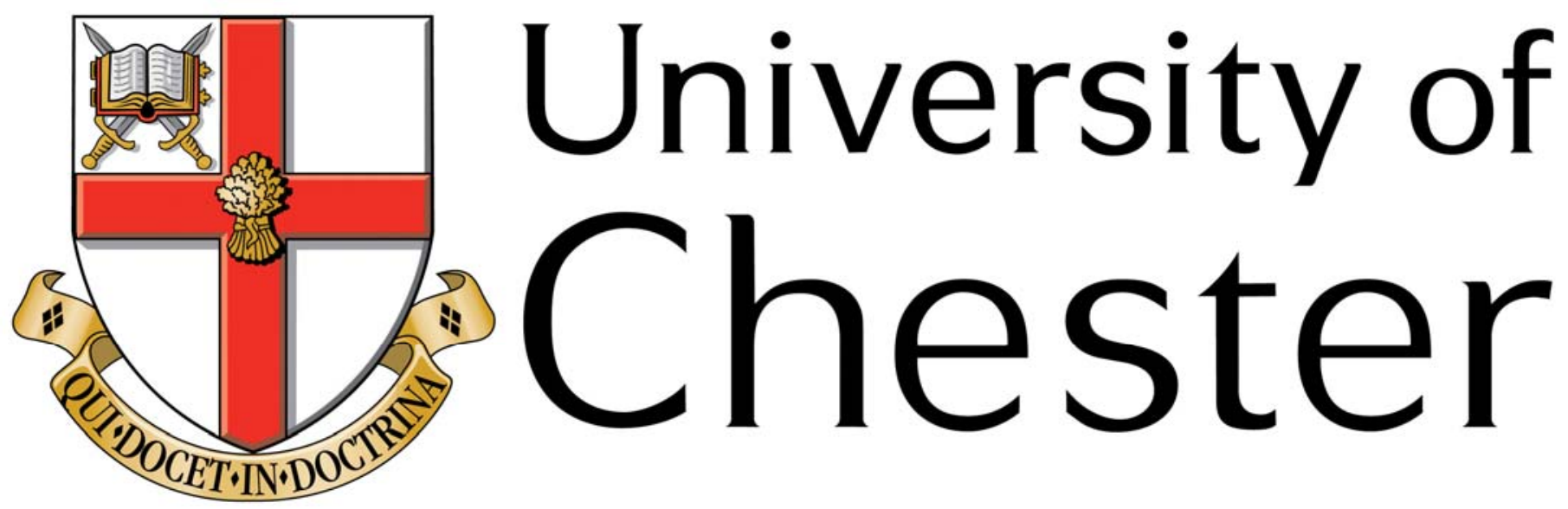

This work has been submitted to ChesterRep - the University of Chester's online research repository

\title{
http://chesterrep.openrepository.com
}

Author(s): M Kearney; C Bradbury; Basma Ellahi; M Hodgson; Miranda Thurston

Title: Mainstreaming prevention: Prescribing fruit and vegetables as a brief intervention in primary care

Date: 2005

Originally published in: Public Health

Example citation: Kearney, M., Bradbury, C., Ellahi, B., Hodgson, M., \& Thurston, M. (2005). Mainstreaming prevention: Prescribing fruit and vegetables as a brief intervention in primary care. Public Health, 119(11), 981-986

Version of item: Author's post-print

Available at: http://hdl.handle.net/10034/10717 


\section{Mainstreaming prevention: Prescribing fruit and vegetables as a brief intervention in primary care}

M. Kearney(a)(b)^, C. Bradbury(c), B. Ellahi(c), M. Hodgson(a), M. Thurston(d)

(a) Castlefields Health Centre, Chester Close, Runcorn WA7 2HY, UK

(b) Community Studies Unit, School of Medical Education, University of Liverpool, Liverpool L69 3GH, UK

(c) Department of Biological Sciences, University College Chester, Chester CH1 4BJ, UK

(d) Centre for Public Health Research, University College Chester, Chester CH1 4BJ, UK

* Corresponding author. Address: Castlefields Health Centre, Chester Close, Runcorn WA7 2HY, UK. Tel.: +44 1928 566671; fax: +44 1928581621.

E-mail address: matt.kearney@btinternet.com (M. Kearney).

\section{Summary}

This paper examines a brief preventive intervention as a model for embedding public health action in primary care.

Background: Low fruit and vegetable intake is a major risk factor for cancer, coronary heart disease and stroke. The recommended intake of five portions per day would reduce death rates from these causes by $20 \%$. However, average daily consumption in the UK is under three portions, and it is significantly lower in men, young people and lower socio-economic groups. In order to tackle risk factors such as poor diet, the white paper Choosing Health promises action and funding to mainstream prevention and transform the NHS from a sickness service to a genuine health service.

The intervention: To promote increased fruit and vegetable consumption, primary care professionals working in a deprived area issue prescriptions which offer the patient discounts on fruit and vegetable purchases. Handover of each prescription to the patient is linked explicitly to key five a day messages. This brief intervention takes 1 -2 min to deploy.

Immediate outcomes: Evaluation is ongoing. However, early feedback suggests that the intervention of prescription plus key messages has a significant impact on patients in highlighting the connection between food and health. Clinicians express satisfaction at having a preventive intervention that can be deployed with confidence and consistency in routine primary care consultations.

Discussion: This brief intervention is presented as a potential model for embedding prevention in the day-to-day work of health professionals. Primary care is a natural setting for the promotion of health, but despite success in implementing some public health programmes, it has a patchy record in primary prevention. The reasons for this are examined, the impact of new contractual and commissioning levers is explored, and a general framework for mainstreaming public health action in primary care is proposed.

\section{Introduction}

Cancer, coronary heart disease (CHD) and stroke account for about $60 \%$ of premature deaths in the UK. There is substantial evidence that low fruit and vegetable intake is a major risk factor for these and other non-communicable diseases. Fruit and vegetables have been shown to have a significant protective 
effect against cancer of the bowel, stomach and breast.(1) The risk of CHD and stroke is also sharply reduced by a higher fruit and vegetable intake.(2)(3) One large study has found a $4 \%$ reduction in CHD risk and a $6 \%$ reduction in stroke risk with each one portion increase in fruit and vegetable consumption.(4) Others have demonstrated a significant fall in blood pressure with rising fruit and vegetable intake.(5)(6)

As well as the decrease in mortality, increased fruit and vegetable consumption has been associated with improved control in long-term conditions such as asthma,(7) COPD,(8) and diabetes,(9) and a reduction in obesity(10) and cataract development.(11)

Overall, it has been estimated that eating five portions per day would reduce mortality from cancer, CHD and stroke by $20 \%$.(12) Indeed, in the case of cancer, the evidence indicates that increasing fruit and vegetable intake to five portions daily is the second most effective prevention strategy after smoking cessation.(13)

The mechanism by which fruit and vegetables improve health is not fully explained. A high fruit and vegetable intake will help to modify overall diet by increasing fibre and reducing fat and sugar intake, and will contribute towards weight reduction. Fruit and vegetables also contain a plethora of essential vitamins and minerals as well as nonnutritive bioactive constituents such as phyto-oestrogens and other phyto-chemicals. Many of these are also antioxidants, which may reduce the risk of cancer and other chronic diseases by destroying free radicals in the body.(14) There is evidence that the protective effects of these components are due to their collective action rather than individual factors working in isolation. Trials of single factors given as high dose supplements have not proved effective and in some cases have been found to be harmful.(15)

On the basis of this evidence, the World Health Organisation recommends a daily intake of $400 \mathrm{~g}$ of fruit and vegetables(16) - defined as at least five $80 \mathrm{~g}$ portions of a variety of fruit and vegetables.(12) However, despite the proven benefits, UK consumption falls considerably short of the recommendation with only $13 \%$ of men and $15 \%$ of women achieving five a day. Average intake for men is 2.7 portions, and for women 2.9 portions. The average decreases significantly with age and the number achieving five a day approaches zero in adults aged 19-24. Consumption is also considerably lower in lower socio-economic groups (2.1 and 1.9 portions, respectively, in men and women on state benefits compared with 2.8 and 3.1 portions in those not on benefits).(17)

Many factors will combine to influence an individual's likelihood of achieving five a day.(19) These include nutritional knowledge, awareness of the health impacts of different foods, attitudes to health promotion messages, skills and confidence in buying, preparing and serving fruit and vegetables, accessibility of shops selling good quality food, and the perishability of fresh fruit and vegetables. Income is also a major determinant of diet. In the UK, food expenditure as a proportion of budget is $16 \%$ for the average household and 30\% for those in the poorest quintile.(18) For those able to shop in supermarkets, food costs are significantly cheaper than in small retail outlets. One recent study found that a shopping basket of 'five a day food' cost 38\% more in rural settings than in urban areas, and that a healthy shopping basket was $35 \%$ more expensive than an unhealthy one.(19) As with other determinants of health, there is a clear socio-economic gradient in fruit and vegetable intake with 
consumption falling in parallel with household income.(20)

The importance of diet and nutrition in improving health and reducing health inequalities has been the subject of increasing UK policy focus in recent years. In England, Saving Lives: Our Healthier Nation(21) highlighted obesity as an important risk factor for CHD and some cancers. The NHS Plan(12) included a commitment to local action on tackling obesity and physical inactivity, and the National Service Frameworks (NSF) for CHD(22) and Diabetes,(2)3 the NHS Cancer Plan(13) and the Public Service Agreements(24)(25) have all included standards and targets relating to improvements in diet and physical activity. The 2004 English white paper, Choosing Health: Making healthier choices easier,(26) gave high priority to improving diet and nutrition, and the linked Food and Health Action Plan(27) detailed action to be taken at national and local levels to reduce intake of fat, salt and sugar, and to increase consumption of fruit and vegetables.

The two Wanless reports(28)(29) were commissioned by the government to identify how best to respond to the growing prevalence of non-communicable diseases and the threat this posed to the sustain-ability of the country's health-care budget. The second report in 2004 emphasised the need to mainstream health promotion and disease prevention, tackling risk factors such as smoking, poor diet and inactivity, if the NHS is to be transformed from a sickness service to a genuine health service.

Choosing Health reflected this emphasis and detailed action to embed prevention in the day-today work of health professionals, promising appropriate funding for training and public health capacity building in primary care.

At a community level, many primary care trusts (PCTs) have responded by launching a wide range of five a day initiatives targeting disadvantaged communities. These have included food cooperatives, cook and taste sessions and support for vegetable allotments. Nationally, the government-funded school fruit and vegetable scheme has been successful in increasing consumption and five a day awareness in children and their parents, particularly in lower socio-economic groups.(30)

At the level of health practitioner, the exercise on prescription scheme allows GPs and others to refer certain categories of patient to fitness programmes. A few PCTs have also experimented with new referral pathways, commissioning commercial organisations to offer weight reduction programmes to patients referred by their GP.(31) But beyond this, primary prevention is poorly developed in primary care.

This paper describes, a brief preventive intervention deployed in primary care consultations to address fruit and vegetable intake as a major risk factor for cancer and cardiovascular disease.

\section{The setting}

The project is set in the Castlefields Health Centre, a primary care centre serving a population of 12,000 in the Castlefields area of Halton, North West England. All four super output areas (SOAs) in Castlefields experience considerable deprivation and one is in the top 2\% most deprived SOAs in England.(32) Mortality rates from all major causes are amongst the worst in the country and it has high levels of unemployment, poverty, single parent families, teenage pregnancy and substance misuse. The practice has 11 doctors and large nursing, health visiting and midwifery teams. 


\section{The intervention}

The project utilises routine primary care encounters to deploy a brief intervention promoting the five a day message to Castlefields patients. At the centre of the scheme is a prescription for fruit and vegetables which GPs, nurses, health visitors and midwives issue to patients on an opportunistic basis. Clinicians are encouraged to take a population approach, not targeting particular patient or disease groups. The project costs of $£ 15,300$ for 1 year have been met by the Neighbourhood Renewal Fund and the Big Lottery Fund.

Each prescription contains four vouchers offering a $£ 1$ discount when $£ 3$ or more is spent on fruit and vegetables. No more than one voucher can be used per transaction and the vouchers can be exchanged at the Halton food cooperative (a non profit-making community enterprise) and at a local retail superstore (Asda).

As the health professionals issue the prescription, they link it explicitly to key five a day messages. The prescription plus key messages comprise the brief intervention, which takes 1-2min to deploy in a consultation. The key messages are:

1. One third of cancer and heart disease deaths could be prevented by better diet.

2. Most people know that the most effective way of preventing cancer is to stop smoking. Well did you know that the next best strategy is to increase fruit and vegetable consumption?

3. If everyone ate five portions of fruit and vegetables a day death rates from cancer, heart disease and stroke could be reduced by $20 \%$. In Halton if we all ate five a day, that would save around 150 lives per year.

To ensure consistency, all clinical staff and receptionists underwent one session of five a day training before the project launch, and this has been supplemented by periodic written updates to remind staff of the project aims and key messages.

The brief intervention does not take place in isolation. Posters and leaflets throughout the health centre advertise the five a day theme as well as local resources such as the food cooperative and cook and taste sessions. There are bowls of fruit at reception and on the clinicians' desks: the fruit is offered to the patients at no cost while staff emphasise the key messages. In addition, a community food worker employed by the practice works with trained volunteers to engage with patients in the waiting room, offering free fruit while giving healthy eating advice.

Evaluation is being conducted using telephone questionnaires and in depth interviews to assess impact of the intervention on changes in consumption and purchasing behaviour, food knowledge and skills, and experience of the health professionals in the use of the prescription as a brief intervention.

\section{Immediate outcomes}

The evaluation is not yet complete, but staff and patients have made observations in the first weeks of the project, which give an early indication of the impact of the intervention. Many patients are visibly surprised at the magnitude of the relationship between food and health, and they appear impressed that doctors and nurses are 
giving as much emphasis to prevention as they do to treatment. The clinical staff have found the intervention to be a high impact way of drawing patients' attention to the food/health connection. Armed with the fruit, prescription and key messages as a framework, they report feeling more confident in discussing diet and nutrition with patients. They also express satisfaction at having a preventive intervention which takes only 1-2 min, and which therefore, can be deployed effectively in routine primary care consultations.

The project has also attracted considerable media interest. Within days of the launch, a number of in-depth and positive articles appeared in the Sunday Express, the Daily Star on Sunday and other newspapers, and interviews were carried on national and local radio stations. Commentators and the public seemed to be captivated by the logic and simplicity of prescribing a healthy diet.

\section{Discussion}

The prescription for fruit and vegetables linked explicitly to key five a day messages could serve as a model for embedding public health action in primary care. As a brief intervention it can be delivered comfortably in the 10min consultation framework and can be reproduced with confidence and consistency by primary care staff.

Wanless made clear that the mainstreaming of health promotion and disease prevention is essential if the NHS is genuinely to transform from a sickness service to a health service. Choosing Health promised action and funding to deliver this by engaging health professionals in the prevention business. What are the prospects of this being achieved?

Primary care is a natural setting for health promotion. Every week in the average British general practice there are hundreds of face-to-face consultations between patients and professionals. One of the hallmarks of primary care is that the relationship between patient and professional is usually long-term and characterised by trust.(33) During consultations with GPs, health visitors, midwives and nurses, health and well-being are always on the agenda, and the wider determinants of health are often highly visible. Approximately $75 \%$ of the population in the UK see their GP in the course of a year, and about 90\% in 5 years.(10) However, these averages obscure the fact that individuals at greatest risk and those with greatest potential for modifying risk-for example children, older people, young parents, those with long-term conditions-are likely to visit their health centre much more frequently. A community survey in 2001 indicated that around 18\% of people in Halton consult their GP more than six times per year.(34) This level of contact represents an unparalleled opportunity for health promotion and preventive interventions.

Despite this potential for public health action, while conventional lists of health promotion settings usually cite locations such as schools, workplaces, universities, hospitals and prisons, they rarely include primary care. This is a striking omission, which almost certainly reflects the presence of significant systemic barriers to the delivery of public health in the primary care setting.

Primary care has been highly successful in implementing some public health programmes. There are, for example, robust systems in place for immunisation, child development and breast and cervical screening. Primary care also has a good track record in secondary prevention through control of blood pressure and use of drugs 
such as aspirin, statins and beta blockers. But its record in primary prevention is patchy for a number of reasons. GPs and community nurses have much greater experience in working with individuals than in addressing factors which influence the health of populations. In addition, their training is usually grounded in the biomedical model, most have limited knowledge and skills in relation to health promotion techniques, and GPs in particular lack confidence in managing issues such as obesity.(26)

A major additional problem for primary care is that it lacks a basic framework for primary prevention. Firstly, few practices routinely collect the core data, which would help predict risk of premature morbidity and mortality. Secondly, the evidence base for what works in preventive interventions is very poorly developed.(35) Thirdly, few prevention pathways exist - that is pathways which guide the patient and clinician from problem identification through risk assessment and option appraisal to intervention by patient, clinician and/or other agency.

The delivery plan for Choosing Health(36) and the linked Planning and Performance Toolkit(37) make clear the obligation on PCTs to build public health capacity and capability, and to embed health promotion and disease prevention in the day-today work of health professionals. In the light of the major constraints on public health action in primary care, how can this paradigm shift be achieved?

PCTs have a number of new levers at their disposal. The new general medical services contract for GPs(38) offers significant flexibility through separate payment arrangements for enhanced services and through local and national adjustments that can be negotiated to the quality and outcomes framework (QOF). The new community pharmacy contract(39) offers similar potential through enhanced services. It is also likely that significant numbers of primary care teams will take on responsibility for practice-based commissioning. Each of these contractual levers offers a major route for commissioning health promotion and prevention services. Other opportunities will arise from the proposed child health promotion programme and the personal and family health plans.

But on their own, these levers will have limited impact in overcoming the systemic barriers to public health action in primary care. What is needed is a new framework to provide a mechanism for mainstreaming prevention. To be effective such a framework would have three essential elements.

Firstly, collection of core data is of paramount importance. Routine recording of body mass index and waist circumference measurements, dietary records (such as fruit and vegetable intake) and physical activity levels would greatly assist practices in assessing need and planning prevention services. These data could be collected by non-clinical staff such as health trainers, health care assistants and receptionists for example.

Secondly, brief interventions are ideal for delivery in the primary care setting. The fruit and vegetable prescription described in this paper offers one model, which can be deployed by clinicians in 1-2 min. Similar interventions could be designed around other aspects of diet and physical activity, and need not be confined to the consulting room: they could also be conducted by health trainers or health care assistants in waiting areas, meeting rooms and pharmacies. 
Thirdly, imaginative new prevention pathways, which utilise existing local resources need to be designed and mainstreamed. Such pathways would allow patients who are overweight, have a poor diet or are physically inactive to be referred to a range of agencies, which already provide services in the community. These could include healthy living centres, cook and taste sessions, allotments, urban walk schemes and tea dance groups, for example. Provider agencies could be voluntary or statutory, and commercial weight management and fitness centres could be commissioned to offer services.

A framework of this nature, generating valuable data and offering solutions in the form of brief interventions and routes of referral, would provide primary care professionals with the practical means to undertake preventive interventions in their day-to-day work.

Finally, the framework and levers need to be developed around a much stronger evidence base if public health action is to become mainstreamed in primary care. Some of this will come from the newly reconstituted National Institute for Health and Clinical Excellence, which will produce regular recommendations relating to the effectiveness and cost effectiveness of interventions. The Prevention NSF described in Choosing Health can also be expected to draw on current evidence to set standards for best practice in prevention. But in addition, PCTs and funding bodies should require that rigorous evaluation based on realistic outcomes is routinely integrated into every new public health project.

But pending these developments, PCTs must face-up to the tension between the need for evidence to justify investment and the growing cost of inaction. When considering which public health interventions to support, it is of course important to take account of existing evidence. But lack of evidence of effectiveness is not the same as evidence of ineffectiveness. Some interventions, though not yet evaluated, nevertheless fall into the category which Jonathan Porritt has classified as the 'blindingly obvious'.(40)

While awaiting the results of evaluations, a reasonable approach for PCTs would be to promote comprehensive prevention strategies, which include both interventions for which there is an evidence base, and interventions which appear to be intuitively rational or to derive from common sense.

\section{References}

(1). Department of Health. Nutritional aspects of cancer. London. TSO 1998.

(2). Department of Health. Nutritional aspects of cardiovascular disease. London. HMSO. 1994.

(3). Ness A, Powles J. Fruit and vegetables and cardiovascular disease: a review. International Journal of Epidemiology 1997;26(1):1-13.

(4). Joshipura K, Ascherio A, Manson J, Stampfer M, Rimm E, Speizer F, Hennekens C, Spiegelman $\mathrm{D}$, Willett W. The effect of fruit and vegetable intake on risk of coronary heart disease. Annals of Internal Medicine. 2001; 134:1106-14.

(5). John J, Ziebland S, Yudkin P, Roe L, Neil H. Effects of fruit and vegetable consumption on plasma antioxidant concentrations and blood pressure: a randomised control trial. The Lancet. 2002; 359:1969-74.

(6). Appel L, Moore T, Obarzanek E, Vollmer W, Svetkey L, Sacks F, Bray G, Vogt T, Cutler J, Winhauser M, Lin P, Karanja N. A clinical trial of the effects of dietary patterns on blood pressure. New England Journal of Medicine. 1997; 336:1117-23.

(7). Forastiere F, Pistelli R, Sestini. Fortes C, Renzoni E, Rusconi F, Dell'Orco V, Ciccone G, Bisant L. 
Consumption of fresh fruit rich in vitamin $C$ and wheezing symptoms in children. Thorax. 2000;55:2838.

8. Butland B, Fehily A, Elwood P. Diet, lung function and lung function decline in a cohort of 2512 middle aged men. Thorax 2000;55:102-8.

9. Sargeant L, Khaw K, Day N, Luben R, Oakes S, Welch A, Wareham N. Fruit and vegetable intake and population glycosylated haemoglobin levels: the EPIC-Norfolk study. European Journal of Clinical Nutrition. 2001;55:342-8.

10. House of Commons Health Committee. Obesity: third report of session 2003-2004. Volume 1. London. TSO. 2004.

11. Taylor A, Jacques P, Epstein E. Relations among ageing, antioxidant status and cataract. American Journal of Clinical Nutrition. 1995;62:1439s-147.

12. Department of Health. The NHS Plan. London. TSO. 2000.

13. Department of Health. The NHS Cancer Plan. London. TSO. 2000.

14. European Heart Network. Food, Nutrition and cardiovascular disease prevention in the European region: challenges for the new millennium. 2002. Accessed online June 2005 at http://www.ehnheart.org/files/ millenium 143851A.pdf.

15. Department of Health. Nutritional aspects of the development of cancer. London. TSO. 1998.

16. World Health Organisation. WHO Fruit and Vegetable Promotion Initiative - report of the meeting, Geneva, 25-27 August 2003. Geneva. WHO. 2003. Accessed online June 2005 at http://www.who.int/dietphysical activity/ publications/f 8tv_promotion_initiative_report.pdf.

17. Henderson L, Gregory J, Swan G. The national diet and nutrition survey. Volume 1. London. TSO. 2002.

18. Department of Health. Food and health action plan: food and health problem analysis for comment. 31 July 2003. Accessed online June 2005 at

http://www.dh.gov.uk/assetRoot/04/06/58/34/04065834.pdf.

19. National Children's Homes. Going hungry: the struggle to eat healthily on a low income. London. NCH. 2004.

20. Department for Environment, Food and Rural Affairs. National food survey datasets. Accessed online June 2005 at http://statistics.defra.gov.uk/esg/publications/nfs/default.asp.

21. Department of Health. Saving Lives: Our Healthier Nation. London. TSO. 1999.

22. Department of Health. National Service Framework for Coronary Heart Disease. London. TSO. 2000.

23. Department of Health. National Service Framework for Diabetes. London. TSO. 2001.

24. HM Treasury. 2002 Spending Review: Public Service Agreements. London. TSO 2002. Accessed online June 2005 at http://www.hmtreasury.gov.uk/Spending_Review/spend_

sr02/psa/spend_sr02_psaindex.cfm.

25. HM Treasury. 2004 Spending Review: Public Service Agreements 2005-2008. London. TSO.

2004. Accessed online June 2005 at

http://www.hmtreasury.gov.uk/spending_review/spend_sr04/psa/spend_sr04_psaindex.cfm.

26. Department of Health. Choosing Health: Making Healthier Choices Easier. London. TSO. 2004.

27. Department of Health. Choosing a Better Diet: a Food and Health Action Plan. London. TSO. 2005.

28. HM Treasury. Securing Our Future Health: Taking a Long-Term View. London. TSO. 2002.

29. HM Treasury. Securing Good Health for the Whole Population. London. TSO. 2002.

30. Department of Health. National school fruit scheme: evaluation summary. London. 2001. TSO.

Accessed online June 2005 at http://www.dh.gov.uk/assetRoot/ 04/01/92/32/04019232.pdf.

31. Avery A, Lavin J, Rees E, Whitehead S. Improvements in self esteem and mental wellbeing as a consequence of patients losing weight through a slimming on referral programme. Oral presentation to the 13th Annual Public Health Forum. Gateshead. 7 April 2005.

32. Office of the Deputy Prime Minister. The English Indices of Deprivation 2004. London. TSO. 2004. 33. Mainous A, Baker R, Love M, Pereira Gray D, Gill J. Continuity of care and trust in one's physician: evidence from primary care in the United States and the United Kingdom. Family Medicine. 2001;33(1):22-7.

34. North Cheshire Health Authority. Health, lifestyle and community survey. Runcorn. North Cheshire Health Authority. 2001.

35. Mulvihill C, Quigley R. The management of obesity and overweight: an analysis of reviews of diet, physical activity and behavioural approaches. Evidence briefing. London. HDA. 2003.

36. Department of Health. Delivering Choosing Health. London. TSO. 2005.

37. Department of Health. LDP 2005-08: Process for sign-off and Choosing Health toolkit. Letter 21

February 2005. Accessed online June 2005 at http://www.dh.gov.uk /assetRoot/

04/10/40/00/04104000.pdf.

38. NHS Confederation. The New CMS Contract. 2003. Accessed online June 2005 at 
http://www.nhsemployers.org/PayAnd-Conditions/pcc_gms_contract_home.asp.

39. Department of Health. Implementing the new community pharmacy contractual framework: information for primary care trusts. 2005. Accessed online June 2005 at

http://www.dh.gov.uk/PublicationsAndStatistics/Publications/PublicationsPolicyAndGuidance/Publicati onsPolicyAndGuidanceArticle/fs/en?CONTENT_ID $=4109256 \mathrm{achk}=/ \mathrm{hpbTh}$.

40. Porritt J. Healthy Environment - Healthy People: the links between sustainable development and health. Keynote address to the 13th Annual Public Health Forum. Gateshead. 5 April 2005. 